\title{
The Role of Nonduality in the Relationship Between Flow States and Well-Being
}

\author{
Julianna M. Lynch ${ }^{1} \cdot$ Allison S. Troy $^{1}$ (D) \\ Accepted: 29 March 2021 / Published online: 27 April 2021 \\ (C) The Author(s) 2021
}

\begin{abstract}
Objectives The current study investigated the hypothesis that the relationship between flow states and well-being is mediated by nondual experiences. Past empirical and theoretical work suggests flow states share similarities with nondual experiences. The current study expanded upon previous work by examining the relationships between flow, nondual experiences, emotion, and well-being.

Methods Students enrolled in various artistic classes $(N=104)$ were surveyed once a week for four weeks. Participants reported on their experiences of flow, nonduality, emotion, and psychological and subjective well-being.

Results Higher scores on measures of both flow $(b=7.03, \mathrm{SE}=0.82, p<.001)$ and nondual experiences $(b=0.17, \mathrm{SE}=0.02, p<$ $.001)$ predicted increased positive emotion immediately after class. Nondual experiences partially mediated this relationship, such that when accounting for nondual experiences, the relationship between flow and positive emotion was significantly decreased $(b=4.30, \mathrm{SE}=0.45, p<.001)$. Longitudinally, nondual experience also mediated the relationship between flow and satisfaction with life (Sobel $t=1.94, \mathrm{SE}=1.06, p=.05$ ). However, while flow predicted increased psychological well-being $(b=0.32, \mathrm{SE}=0.14, p=.02)$ after the four weeks, nondual experience did not $(b=-0.003, \mathrm{SE}=0.002, p=.13)$.

Conclusions These findings suggest that flow states may facilitate some features of nonduality and share similarities with meditative states. Additionally, the link between flow and well-being may be explained by its similarities to meditative states, and that creative activities could be useful in fostering well-being.
\end{abstract}

Keywords Flow $\cdot$ Nonduality $\cdot$ Well-being $\cdot$ Emotion $\cdot$ Creativity $\cdot$ Art

Most people engage in a handful of activities or hobbies they find intrinsically rewarding. This type of activity is performed because the experience or process itself is an enjoyable one, and not necessarily because it achieves a certain outcome or result. These activities are often creative and can be life passions, such as creating art or music, writing, dancing, or acting. Different forms of movement such as exercise and sports are also common. Though these types of activities can and do involve external rewards, such as winning competitions or gaining recognition, individuals are intrinsically motivated to continue doing them. Not only are these activities rewarding in and of themselves, but engaging in them can also help individuals cope with life's challenges (Bien, 2005; Fritz \&

Allison S. Troy

atroy@fandm.edu

1 Department of Psychology, Franklin \& Marshall College, Lancaster, PA, USA
Avsec, 2007; Hughes \& da Silva, 2011; Svensk et al., 2009). For instance, some individuals play the piano, go hiking, or even knit as a way to deal with stress (Adey, 2018). These activities frequently help individuals enter into what Csikszentmihalyi (2014) calls the flow state. During a state of flow, individuals become absorbed in the activity they perform as it provides a challenge-skill balance which keeps the individual engaged, without falling into boredom or anxiousness.

Much of the early empirical work on flow included experience sampling, or qualitative descriptions of flow experiences to better capture and understand their nature (Csikszentmihalyi, 2014). Investigating flow through the use of experience sampling helped define the nine facets of the flow state, which led to the development of the Flow State Scale (Jackson \& Marsh, 1996). Using this scale to examine flow experiences provided a way to measure varying degrees of flow, demonstrating that flow is not an all-or-nothing phenomenon, but that individuals often experience varying 
degrees of absorption into the flow state (Csikszentmihalyi, 2014; Fritz \& Avsec, 2007; Jackson \& Marsh, 1996).

The nine dimensions of the flow state include challengeskill balance, clear goals, unambiguous feedback, concentration, transformation of time, action-awareness merging, paradox of control, loss of self-consciousness, and autotelic experience (Csikszentmihalyi, 2014; Jackson \& Marsh, 1996). The ideal flow opportunity presents high challenge situations to individuals who possess sufficient skills to meet those challenges. For example, intermediate rock climbers may choose difficult routes to suit their abilities and challenge their strengths, while avoiding routes too far beyond their skill level that may seem impossible or overwhelming. Individuals typically set out with clear goals in mind and are aware of how well they are performing in reference to those goals. By the same token, the value of flow experiences is often found in the journey or process, and the activities are considered autotelic experiences. While a climber knows the goal of the activity is to complete the route, the reward of climbing comes from overcoming physical and mental challenges during the climb. Individuals experiencing flow can also become so deeply concentrated on the task at hand that their sense of time may speed up or slow down. The experience of actions and awareness merging refers to the effortless feeling that flow states often invoke. Indeed, individuals often report performing automatically without thinking too deeply (Adey, 2018; Csikszentmihalyi, 2014). With heightened focus on the task, other self-focused concerns often dissolve away, as described by the facet "loss of self-consciousness." The paradox of control describes the perfectly calibrated and sometimes mysterious feeling of experiencing a sense of control over your actions despite not having to contemplate deeply what your next move will be (Csikszentmihalyi, 2014). The mechanics of the task happen automatically yet deliberately, hence the paradox.

Flow experiences have been positively linked to well-being in past research (Collins et al., 2009; Csikszentmihalyi, 2014; Fritz \& Avsec, 2007; Rankin et al., 2018). However, many past investigations between flow and well-being often only measured one particular aspect of well-being. Well-being refers to psychological wellness both in the short- and long-term (Ryff \& Keyes, 1995) and scientific definitions of well-being include two different conceptualizations. One definition of well-being is subjective well-being, which refers to positive and negative mood, satisfaction with life, and includes the idea that individuals can subjectively evaluate their own happiness (Ryan \& Deci, 2001). On the other hand, psychological well-being focuses on the internal feelings and perspectives a person holds towards themselves, others, and life in general, and includes more abstract ideas of happiness such as, fulfillment of life-long goals and living in accordance with one's values (Ryan \& Deci, 2001; Ryff, 1989). Both subjective and psychological well-being are important indicators of successful coping with life stress and have also demonstrated links to physical health (McGonigal, 2015; Ryan \& Deci, 2001). Thus, well-being is an important indicator of successful functioning overall (Ryan \& Deci, 2001). Furthermore, maintaining well-being in the face of stress is a vital aspect of living a meaningful and happy life (Ryan \& Deci, 2001; Ryff, 1989).

Flow experiences have been considered to play a role in psychological well-being because flow activities provide an opportunity for growth and the achievement of goals in the long-term (Csikszentmihalyi, 2014; Ryan \& Deci, 2001; Wrigley \& Emmerson, 2011). Previous research has shown that in a sample of orchestra and singing students, dispositional tendencies towards flow experiences predicted increased subjective well-being and were related to more positive emotion (Fritz \& Avsec, 2007). Another recent study examining the relationship between flow experiences and subjective well-being during a waiting period found that both law and doctoral-level students who reported higher frequencies of flow occurrences within the last week also reported fewer negative emotions, less worry, and more positive emotions during the waiting period for exam results or potential job offers (Rankin et al., 2018). In an experimental study, undergraduate students who played a flow-inducing version of Tetris (the challenge-level increased by completing successful moves) also reported more positive and fewer negative emotions than both a boredom (no increase in challenge-level) and an overload condition (too much increase in challenge-level; Rankin et al., 2018). Although playing Tetris may not be considered as meaningful or engaging as other forms of flow activities, these findings demonstrate a robust relationship between flow experiences and positive outcomes.

Although previous studies support the link between flow and certain aspects of well-being, there remains the important question of why flow experiences demonstrate such a strong link in the first place. One possible explanation for the link between flow states and short-term well-being (positive and negative emotion) is that immersive activities can promote concentration while potentially decreasing self-awareness, which leads to a decrease in the intensity of negative emotions (Gross, 1998; Leary \& Gohar, 2014). Similarly, flow encourages a loss of self-consciousness that might otherwise cause the person to worry about themselves or others (Csikszentmihalyi, 2014). Yet, merely losing a self-focus does not seem to capture the transformative experience that flow often produces. Instead, a contemplative perspective may shed light on the mechanism by which conceptions of the self, emotions, and reality are redefined during a state of flow, and why immersive and creative activities have the potential to catalyze a shift in attentional focus and selfconceptualization that leads to well-being.

The integration of self during flow activities parallels ideas found in the larger philosophical perspective of nonduality. Nonduality describes a unification between subject and object, such that boundaries between self and world dissolve. This 
perspective permeates many different religious, mystical, and philosophical traditions, and can be explicitly found in the Hindu schools of Advaita Vedānta and Kashmiri Shaivism, Mahāyāna Buddhism, and Tibetan Bon Dzogchen and implicitly present in Daoist traditions (Blackstone, 2015; Krägeloh, 2018; Wright, 2017).

For example, flow shares conceptual similarities with the Daoist description of wu-wei, or "non-doing." In the Dao de Jing, the ancient Chinese philosopher, Lao Tzu describes the way of the Dao as an embodiment of dichotomies (Lao Tzu, 4th century BC/1991). He encourages that we behave like water; fluid and flexible, yet strong and powerful. For our endeavors, this means we should strive for a feeling of effortlessness. It seems counter-intuitive at first to imagine how disengagement from a goal might be more efficient in achieving that goal. We can conceptualize non-doing as behaving in an effortless way to execute a task that would otherwise be considered challenging.

The Dexterous Butcher is a famous proverb by Zhuangzi that describes a cook cutting up an ox (de Bary \& Bloom, 1968). A beginner would "hack" away at the meat, but the butcher knows the way of non-doing, and can effortlessly glide the knife through the meat while avoiding all the joints and ligaments. Like flow, there is a balance of challenge and skills, a merging of action and awareness, and the focus is no longer on the self. In such an absorbed state, the self is not merely ignored, but rather transforms as the person becomes integrated into the activity. The subject (the butcher) and the object (cutting the ox) have merged into a single dynamic unit. This experience, commonly described as becoming One with the object, is a feature of nonduality.

This transformation of self differs from the typical everyday experience, which contains varying degrees of separation between ourselves and what we consider the outside world. While nonduality describes a perspective about the relationship between subject-object, fully realizing nonduality, or nondual awareness, is a non-representational and reflexive consciousness in which distinctions between subject and object no longer endure and is spontaneously realized (Josipovic, 2019; Krägeloh, 2018). While phenomenological aspects of nonduality may be realized and described during particular experiences, nondual awareness describes consciousness that is inherently aware of itself (Dunne et al., 2019; Josipovic, 2019). This realization is reflexive and non-conceptual, meaning that the awareness knows itself instantly and does not contain mental content or representations. Some scholars argue that scientific investigation cannot capture the true experience of nondual awareness because the very act of describing or measuring the experience inadvertently ruins its purely non-representational and non-conceptual nature (Josipovic, 2019; Krägeloh, 2018). However, theoretical and neuroscientific investigations attempt to dispel confusion about the experience of nonduality by drawing distinctions between the spontaneous realization of nondual awareness in its pure form, and other experiences of nonduality that still contain mental content and are realized through reflection (Josipovic, 2010; 2014; 2019). Berman and Stevens (2015) found evidence to suggest that nondual awareness during meditation has distinct EEG markers compared to those markers found during meditation practice in general. Additionally, some scales have been created to measure aspects of nondual experiences that still contain mental content and remain useful in understanding how nonduality affects cognitive and affective features of experience (Hanley et al., 2018; Krägeloh, 2018; Mills et al., 2018). Aspects of nonduality can still benefit wellbeing, even if realized after reflection or guidance (Blackstone, 2015), and previous work has investigated nonduality using self-report measures (Hanley et al., 2018).

The Nondual Awareness Dimensional Assessment (Hanley et al., 2018) contains items that describe experiences with nondual features, such as merging of self and environment. It is important to note that the non-conceptual, nonreflective form of nondual awareness mentioned above is not necessarily captured in the Nondual Awareness Dimensional Assessment. However, the scale provides a way to measure features of nondual experience that may or may not contain mental content.

Nondual awareness contains properties that are often discussed in the context of meditation and contemplative traditions, such as emptiness, unity, being, luminosity, and bliss, among others (Josipovic, 2019). These components relate to each other in important ways, for instance, as boundaries between subject-object dissolve, a unity among all things presents itself. This could manifest as an understanding of the sameness of self and others, individual and cosmos, or person and present moment. Although it may be inconclusive whether an individual experiences pure nondual awareness, experiences containing nondual features are often illuminating and blissful, and demonstrate the psychological and spiritual benefits of nonduality generally (Blackstone, 2015; Hanley et al., 2018). To put another way, one's sense of reality is reshaped, and this change in perception and understanding facilitates a sense of well-being (Blackstone, 2015; Dorjee, 2016). Indeed, Hanley et al. (2018) found that trait measures of the experience of nondual awareness predicted both psychological and subjective well-being.

Although typically associated with meditation, there is some consensus that nondual experiences may occur in other relevant contexts, beyond that of meditation (Blackstone, 2015; Hanley et al., 2018). Certain dimensions of flow, such as the loss of self-consciousness, the merging of action-awareness, and the autotelic experience, suggest that some aspects of nondual awareness may underlie the psychological components described during flow states. According to Josipovic (2019), nondual awareness is an underlying awareness in all conscious experiences, even if left unrealized. It could be that 
flow states tap into or uncover portions of this nondual awareness, revealing nondual features of experience to the individual. Realizing nonduality holds great therapeutic implications as the mental, emotional, physical, and spiritual aspects of our existence begin to merge (Blackstone, 2015). The subtle sensing abilities used to tune into our emotions and perceptions become honed as we become simultaneously grounded in the present moment and expand this unified experience beyond our own consciousness and extend it towards our relationships with others (Blackstone, 2015). Nondual experience can regulate emotions by alleviating self-focused perceptions, creating more openness within the body and mind, and thus allowing for the transformation of the subject-object boundaries to take place. Given the unifying aspects of the flow state, such as the merging of actions with awareness, flow may facilitate emotion regulation and lead to well-being by cultivating nondual experiences. With subject and object no longer separate, emotions may be channeled through our engagement with an activity. Removing boundaries between self and object is different than ignoring the self entirely, as the latter might prohibit the person from processing emotions at all, such as in avoidance coping (Roth \& Cohen, 1986; Sheppes \& Meiran, 2007, 2008). By experiencing some features of nondual awareness, the self becomes integrated in such a way that would allow emotions to still be processed, while removing the ordinary self-focus that would otherwise increase the difficulty of emotional processing.

Although many types of activities can induce the flow state, sports and professional athletes have been the primary focus of past investigations (Connolly \& Tenenbaum, 2010; Jackson et al., 2001; Jackson \& Marsh, 1996). Previous work has expanded upon this by validating the measure of the flow state in musical performances (Fritz \& Avsec, 2007; Wrigley \& Emmerson, 2011). However, one study examining orchestra students found that immediately following their performance exam, most students did not report being absorbed or enjoying their performance experience, most likely due to evaluative pressure (Wrigley \& Emmerson, 2011). The delicate challenge-skill balance of flow experiences suggests that high pressure situations may hinder performers' ability to transition into the flow state. For this reason, more research is needed to capture a diverse range of activities and skill levels that may investigate nonduality in a context beyond meditation. This would allow for the examination of flow and nondual experiences in an ordinary (i.e., not during a performance) setting.

The present study aimed to examine if flow state experiences are associated with increased positive and decreased negative emotion in the short-term, and positively associated with psychological and subjective well-being in the longerterm. We hypothesize that the experience of nonduality, during which the distinction between subject and object disappear, mediates the relationship between flow states and well- being. To clarify, the current study is mainly concerned with experiences of nonduality and not necessarily pure nondual awareness.

\section{Method}

\section{Participants}

An a-priori power analysis assuming a small effect size in a linear multiple regression model with three predictors indicated a target sample of 74 participants. In order to account for possible attrition over the course of the four weeks, we aimed to recruit 100 participants. One hundred and four undergraduate students (female $=75$, male $=26$, and nonbinary $=3$ ) participated in the study. Students were between 18 and 22 years old $(M=19.83, S D=1.30)$. The ethnic and racial composition of the sample was $74 \%$ White, $5.8 \%$ Black or African American, 17.3\% Asian, and 6.7\% Latinx/Hispanic.

Students were involved in one of the following organizations or classes: Orchestra $(N=40)$, Chamber Singers $(N=$ 13), A Capella $(N=1)$, Dance Company $(N=8)$, Senior Art Capstone $(N=2)$, Sound \& Movement $(N=4)$, Dance History ( $N=4$; involved daily movement component), Acting I $(N=$ $10)$, Intro to Ballet $(N=9)$, Sculpting $(N=3)$, Physical to Digital Design $(N=1)$, Intermediate Modern Dance Composition \& Technique $(N=3)$, Intro to Drawing $(N=$ $5)$, and one unidentified class $(N=1$; participant did not report which class they were in). Participants were compensated $\$ 5$ each for completing the survey for Weeks 1 and 4, and \$3 each for completing the surveys for Weeks 2 and 3, and a $\$ 4$ bonus for completing all four of the surveys (a maximum total of $\$ 20$ for each participant).

For Week 1, we collected 104 observations which made up the total sample. Completion rates across the subsequent weeks were as follows: Week $2=79.80 \%$ ( 83 observations), Week $3=78.84 \%$ (82 observations), Week $4=74.03 \%$ (77 observations).

\section{Procedure}

Recruitment involved obtaining a roster list of emails from various creative, artistic, and/or musical classes at the instructor's discretion and with permission. One month into the spring semester, we sent emails to the lists of rosters we obtained directly after their corresponding class or rehearsal finished for that day. For example, if one student's class ended at $2 \mathrm{pm}$ on Mondays, and another student's class ended at $8 \mathrm{pm}$, the first student received our email at $2 \mathrm{pm}$ while the second received the email at $8 \mathrm{pm}$. This ensured that students interested in participating could complete Week 1 of the survey immediately after their class or rehearsal finished. The email detailed the nature of the study and included a link to Week 1 
of the survey which directed them to the online survey on Qualtrics. This aimed to improve response accuracy and memory. Reminders to complete the survey were sent at $10 \mathrm{pm}$ to everyone who had not yet completed the survey for that day, and we also informed participants that they must complete the survey before midnight that night for their response to count. If a participant submitted a response after midnight, we considered the response as valid if it did not exceed $24 \mathrm{~h}$ since the end of the class. There were no responses that exceeded this 24-h cut-off.

The surveys took place online once a week for four weeks. This allowed us to obtain multiple time points of data for each participant. Students who opted-in for Week 1 were recontacted via email one week later at the same time (at the end of the class) to complete Week 2. All participants who completed Week 1 received emails for Weeks 2-4, even if they missed a week of surveying. Classes typically took place twice a week, but students were only contacted on one of these days per week to complete the survey. The day of surveying remained consistent from week to week, for example, if a student had class on Mondays and Wednesdays, they consistently received the survey on Mondays each week. In one case, a participant completed two surveys in one week, because the second served as a "make-up" survey for a previous class that was cancelled. Surveying once a week allowed participants to have a substantial break in between questionnaires, which aimed to decrease cognitive load and also attempted to prevent increased self-focused thinking during class.

Weeks 1 and 4 both included the Psychological WellBeing Scale (Ryff \& Keyes, 1995), the Satisfaction with Life Scale (Diener et al., 1985), the Flow State Scale (Jackson \& Marsh, 1996), the Nondual Awareness Dimensional Assessment (Hanley et al., 2018), and the Positive and Negative Affect Scale (Watson et al., 1988). Weeks 2 and 3 only included the Flow State Scale (Jackson \& Marsh, 1996), Nondual Awareness Dimensional Assessment (Hanley et al., 2018), and the Positive and Negative Affect Scale (Watson et al., 1988). See Fig. 1 for a flow chart of the study procedure.

\section{Measures}

Nondual experience We used a modified version of the Nondual Awareness Dimensional Assessment (NADA) 13item scale to measure experiential aspects of nonduality typically associated with meditation (Hanley et al., 2018). The NADA aims to measure experiential effects of nondual awareness, such as bliss and self-transcendence. This scale was not used here to capture "pure" nondual awareness - a realization of consciousness itself, void of content and phenomena, (Josipovic, 2014, 2019), but instead was used to gather insight about subjects' reports of their experience that may have contained nondual features as well as phenomenal content. We adapted the language in the full 13-item scale (Nondual Awareness Dimensional Assessment-Trait, or NADA-T) to reflect present-focused questions (e.g., "I have experienced the insight that all is One" was changed to "I experienced the insight that all was One"). Participants were instructed to answer the questions in reference to what they had experienced in class or rehearsal that particular day. Although Hanley et al. (2018) designed a three-item state measure of nondual awareness (NADA-State), we wanted to use the full 13-items from the NADA-T to ensure that the construct was fully captured. Items were answered on the Likert scale originally used for the NADA-State scale, ranging from 1 (not at all) to 10 (very much). We calculated a sum score for each respondent for each of the four weekly surveys (possible range from 13 to 130). The scale displayed high reliability for Weeks $1-4: \alpha=.96, \alpha=.99, \alpha=.98$, and $\alpha=$ .98. The score ranges for each week were as follows: Week 1 range 15-130, Week 2 range 13-130, Week 3 range 9-120, Week 4 range 11-125. Weekly nondual experience sum scores were averaged across all four weeks to yield a grand mean for each individual. Grand nondual experience means displayed homoscedasticity, as assessed by visual inspection of a plot of standardized residuals versus standardized predicted values on the Psychological Well-Being Scale (PWB) and Satisfaction with Life Scale (SWLS) on both Weeks 1 and 4. Residuals were normally distributed as assessed by visual inspection of a normal probability plot.

Flow state The Flow State Scale (FSS) is a 36 -item scale measuring optimal experience, or flow at the state level (Jackson \& Marsh, 1996). The FSS measures the nine dimensions or facets of flow: challenge-skill balance, actionawareness merging, clear goals, unambiguous feedback, concentration on task at hand, paradox of control, loss of selfconsciousness, transformation of time, and autotelic experience. Participants were instructed to answer the questions in reference to what they had experienced in class or rehearsal
Fig. 1 Flow chart showing the timeline of the study procedure. Surveys were sent out once a week and the scales included for each day are listed in the order they appeared in the online survey
Week 1

Psych. Well-Being Satisfaction with Life Flow State

Pos. \& Neg. Emotion

Nondual Experience
Week 2

Flow State

Pos. \& Neg. Emotion

Nondual Experience
Week 3

Flow State

Pos. \& Neg. Emotion

Nondual Experience
Week 4

Psych. Well-Being Satisfaction with Life Flow State

Pos. \& Neg. Emotion Nondual Experience 
that particular day. Items were answered on a Likert scale ranging from 1 (strongly disagree) to 5 (strongly agree). We created a mean score for each respondent which averaged answers across all nine dimensions on the FSS (possible range from 1 to 5). We also created separate mean scores for each dimension (possible range from 1 to 5 ) to use in exploratory analyses. The scale displayed high reliability for Weeks $1-4$ : $\alpha=.91, \alpha=.92, \alpha=.93$, and $\alpha=.95$. The score ranges for each week were as follows: Week 1 range 2.22-4.81, Week 2 range 2.25-4.64, Week 3 range 2.06-5.00, Week 4 range 1.75-4.81. Weekly flow means were averaged across all four weeks to yield a grand mean for each individual. Grand flow means displayed homoscedasticity, as assessed by visual inspection of a plot of standardized residuals versus standardized predicted values on the Psychological Well-Being Scale (PWB) and Satisfaction with Life Scale (SWLS) on both Weeks 1 and 4. Residuals were normally distributed as assessed by visual inspection of a normal probability plot.

Emotion Feelings of positive and negative emotions were assessed using the Positive and Negative Affect Scales (PANAS; Watson et al., 1988). The PANAS provides 10 positive and 10 negative words which respondents mark on a Likert scale from 1 (very slightly or not at all) to 5 (extremely) according to how much they felt or experienced the emotion word. Participants were instructed to answer the questions in reference to what they had felt immediately after class or rehearsal that particular day. We added scores for the positive emotion words (interested, excited, strong, enthusiastic, proud, alert, inspired, determined, attentive, active) to create a positive emotion sum score for each respondent. We also added scores for the negative emotion words (distressed, upset, guilty, scared, hostile, irritable, ashamed, nervous, jittery, afraid) to create a negative emotion sum score for each respondent. Positive and negative emotion sum scores could individually range from 10 to 50 . The positive emotion items displayed high reliability for Weeks $1-4: \alpha=.92, \alpha=.90$, $\alpha=.91$, and $\alpha=.95$. The score ranges for positive emotion items for each week were as follows: Week 1 range 13-50, Week 2 range 13-50, Week 3 range 15-49, Week 4 range 1150 . The negative emotion items displayed good reliability for Weeks 1-4: $\alpha=.76, \alpha=.83, \alpha=.83$, and $\alpha=.73$. The score ranges for negative emotion items for each week were as follows: Week 1 range 10-34, Week 2 range 10-38, Week 3 range $10-32$, Week 4 range $10-31$.

Well-being (Psychological) We measured levels of psychological well-being at Week 1 and Week 4 using the 18-item Psychological Well-Being Scale (PWB; Ryff \& Keyes, 1995), containing items regarding six dimensions of wellbeing including autonomy, environmental mastery, personal growth, positive relations with others, purpose in life, and selfacceptance. Participants were instructed to answer the questions in reference to how they felt in general. Items were answered on a Likert scale ranging from 1 (strongly disagree) to 6 (strongly agree) and negatively phrased items were reverse scored. We averaged the responses across all 18 -items to create a mean score for each respondent for each time point (possible range from 1 to 6 ). The scores displayed high reliability at both Weeks 1 and $4: \alpha=.79$ and $\alpha=.75$. The score ranges for each week were as follows: Week 1 range 3.065.72 and Week 4 range 3.17-5.78.

Well-being (Subjective) We also measured subjective wellbeing at Week 1 and Week 4 using the Satisfaction with Life Scale (Diener et al., 1985), a five-item scale measuring satisfaction and contentment with one's life. Participants were instructed to answer the questions in reference to how they felt about their life in general. Items were answered on a Likert scale ranging from 1 (strongly disagree) to 7 (strongly agree). We created sum scores for each respondent for each time point by totaling the responses given for each item (possible range from 5 to 35). The scores displayed high reliability at both Weeks 1 and $4: \alpha=.78$ and $\alpha=.84$. The score ranges for each week were as follows: Week 1 range 7-34 and Week 4 range 5-35.

\section{Data Analyses}

As a preliminary analysis, we ran descriptive, skewness, and kurtosis statistics of the mean scores of flow, nondual experience, and well-being measures. Our sample included participants from both introductory level classes and upper-level classes. We inspected the mean scores of flow and nondual experience of the introductory and upper-level classes by conducting an independent samples $t$-test. All statistical tests were conducted using SPSS Statistical Software unless stated otherwise.

To investigate our primary hypothesis, we conducted a series of mixed linear models using $\mathrm{R}$ Studio to examine the relationships between experiences of flow, nondual experience, and positive and negative emotion, all of which were reported immediately after class. To account for the hierarchical structure of the data (i.e., weeks nested within persons), we fit random intercept models (i.e., intercepts were allowed to vary by person) using the lme4 package (Bates et al., 2015) in R version 3.2 (R Core Team, 2015). Following the recommendation of Enders and Tofighi (2007), all predictors were groupmean centered (i.e., centered around each individual's mean score). We first examined a series of random intercept models to test our hypotheses regarding positive emotion. We next examined a series of random intercept models testing our hypotheses regarding negative emotion. 
We also investigated the relationship between flow, nondual experience, and changes in more global measures of well-being across the entire 4-week time period. We ran multiple regression models with grand flow means and grand nondual experience means entered as independent variables and mean psychological well-being scores on Week 4 entered as the dependent variable. We also entered psychological well-being means on Week 1 as an additional independent variable to account for the change in psychological wellbeing over the four weeks. Next, we ran multiple regression models with grand flow means and grand nondual experience means entered as independent variables and satisfaction with life scores on Week 4 entered as the dependent variable. We also entered satisfaction with life scores on Week 1 as an additional independent variable to investigate the change in satisfaction with life over the four weeks. Although significantly correlated, flow mean scores and nondual experience sum scores did not display severe multicollinearity. In both the well-being and satisfaction with life regression models, grand flow and grand nondual experience had a variance inflation factor (VIF) of 1.65. Severe multicollinearity typically displays values between 5 and 10 .

As an exploratory analysis, we averaged responses on each of the nine dimensions of the flow state (challenge-skill balance, action-awareness merging, clear goals, unambiguous feedback, concentration, transformation of time, autotelic experience, paradox of control, and loss of self-consciousness) and the two dimensions of nondual experience included on the Nondual Awareness Dimensional Assessment (selftranscendence and bliss) across all four weeks to examine the relationships between the specific dimensions of each scale.

\section{Results}

\section{Preliminary Analyses}

Descriptive statistics of the mean scores on the flow, nondual experience, and well-being measures are summarized in Tables 1 and 2. None of the variables in the regression model displayed skewness as assessed by test statistic values that were between -.5 and .5 , meaning that the distributions of means were approximately symmetric (Bulmer, 1979). Grand flow mean displayed a skewness of $-.07(\mathrm{SE}=.24)$. Grand nondual mean displayed a skewness of .24 $(\mathrm{SE}=.25)$. Psychological well-being mean (Day 1) displayed a skewness of - .1 ( $\mathrm{SE}=.24)$. Psychological well-being mean (Week 4) displayed a skewness of $.13(\mathrm{SE}=.28)$. Life satisfaction (Week 1) displayed a skewness of .27 ( $\mathrm{SE}=.24)$. Life satisfaction (Week 4) displayed a skewness of $.37(\mathrm{SE}=.28)$. None of the variables in the regression model displayed excessive kurtosis, as assessed by test statistic values that were between -2 and 2 (George \& Mallery, 2010). Grand flow
Table 1 Descriptive statistics for predictor and outcome variables in the linear regression models

\begin{tabular}{llllll}
\hline & $N$ & Min & Max & Mean & SD \\
\hline Grand Flow & 98 & 2.39 & 4.62 & 3.56 & 0.46 \\
Grand Nondual Experience & 94 & 13.50 & 116.75 & 58.47 & 27.78 \\
Psych. Well-Being Week 1 & 102 & 3.06 & 5.72 & 4.42 & 0.56 \\
Psych. Well-Being Week 4 & 76 & 3.17 & 5.78 & 4.42 & 0.52 \\
Satisfaction with Life Week 1 & 100 & 7.00 & 34.00 & 22.26 & 5.60 \\
Satisfaction with Life Week 4 & 76 & 5.00 & 35.00 & 23.22 & 5.97 \\
\hline
\end{tabular}

Grand Flow = the mean of the participants' scores on the Flow State Scale (Jackson \& Marsh, 1996) averaged across all four weeks; Grand Nondual Experience $=$ the mean of the participants' sum scores on the Nondual Awareness Dimensional Assessment averaged across all four weeks, questions adapted from the NADA-Trait scale (Hanley et al., 2018) to reflect a state measure; Psych. Well-Being $=$ the mean of the participants' scores on the Psychological Well-Being Scale (Ryff \& Keyes, 1995) for Weeks 1 and 4; Satisfaction with Life = the mean of the sum scores on the Satisfaction with Life Scale (Diener et al., 1985) for Weeks 1 and 4

mean displayed a kurtosis of .01 $(\mathrm{SE}=.48)$. Grand nondual mean displayed a kurtosis of $-.81(\mathrm{SE}=.49)$. Psychological well-being mean (Week 1) displayed a kurtosis of .54 (SE = .47). Psychological well-being mean (Week 4) displayed a kurtosis of .23 ( $\mathrm{SE}=.55)$. Life satisfaction (Week 1) displayed a kurtosis of $.29(\mathrm{SE}=.48)$. Life satisfaction (Week 4) displayed a kurtosis of $.17(\mathrm{SE}=.55)$.

Flow means were significantly correlated with nondual experience means, $r=.558, n=94, p<.001$.

Participants in introductory courses did not experience substantially different amounts of flow overall $(M=3.55, S D=$ $0.54)$ than participants in upper-level courses $(M=3.54, S D=$ $0.43 ; t(91)=0.05, p=.96)$. Similarly, participants in introductory courses did not experience substantially different

Table 2 Descriptive statistics for scores on the Flow State Scale and Nondual Awareness Dimensional Assessment for each week

\begin{tabular}{llllll}
\hline & $N$ & Min & Max & Mean & SD \\
\hline Flow Week 1 & 98 & 2.22 & 4.81 & 3.51 & 0.49 \\
Flow Week 2 & 81 & 2.25 & 4.64 & 3.57 & 0.51 \\
Flow Week 3 & 81 & 2.06 & 5.00 & 3.62 & 0.55 \\
Flow Week 4 & 76 & 1.75 & 4.81 & 3.66 & 0.61 \\
Nondual Experience Week 1 & 93 & 15.00 & 130.00 & 61.88 & 28.38 \\
Nondual Experience Week 2 & 79 & 13.00 & 130.00 & 58.90 & 29.89 \\
Nondual Experience Week 3 & 81 & 9.00 & 120.00 & 57.04 & 30.57 \\
Nondual Experience Week 4 & 76 & 11.00 & 125.00 & 58.14 & 33.73 \\
\hline
\end{tabular}

Flow $=$ participants' mean scores on the Flow State Scale (Jackson \& Marsh, 1996) for each week; Nondual Experience = participants' mean scores on the Nondual Awareness Dimensional Assessment for each week, questions adapted from the NADA-Trait scale (Hanley et al., 2018) to reflect a state measure 
Table 3 Results of mixed linear models examining the day-level relationships between flow, nondual experience, and positive emotion

\begin{tabular}{|c|c|c|c|c|c|c|c|}
\hline & \multirow[t]{2}{*}{$\mathrm{b}$} & \multirow[t]{2}{*}{ SE } & \multirow[t]{2}{*}{$N$} & \multicolumn{2}{|c|}{$95 \% \mathrm{CI}$} & \multirow[t]{2}{*}{$t$} & \multirow[t]{2}{*}{$p$} \\
\hline & & & & Lower & Upper & & \\
\hline Flow predicting Pos. Emotion & 7.03 & 0.82 & 329 & 5.31 & 8.60 & 8.56 & $<.001$ \\
\hline Flow predicting Nondual Experience & 16.26 & 2.28 & 329 & 12.08 & 20.86 & 7.13 & $<.001$ \\
\hline Nondual Experience predicting Pos. Emotion & 0.17 & 0.02 & 328 & 0.13 & 0.22 & 8.14 & $<.001$ \\
\hline Flow predicting Pos. Emotion controlling for Nondual Experience & 5.08 & 0.85 & 328 & 3.29 & 6.78 & 5.94 & $<.001$ \\
\hline Nondual Experience Predicting Pos. Emotion controlling for Flow & 0.12 & 0.02 & 328 & 0.07 & 0.16 & 5.39 & $<.001$ \\
\hline
\end{tabular}

b indicates unstandardized coefficients. Flow = the mean of the participants' scores on the Flow State Scale (Jackson \& Marsh, 1996) measured immediately after class each week; Nondual Experience $=$ the mean of the participants' scores on the Nondual Awareness Dimensional Assessment measured immediately after class each week, questions adapted from the NADA-Trait scale (Hanley et al., 2018) to reflect a state measure; Pos. Emotion $=$ the mean of the participants' scores on the positive emotion items of the Positive and Negative Affect Scales (Watson et al., 1988) measured immediately after class each week. Results of the Sobel test for mediation are reported in text

amounts of nondual experience overall $(M=61.70, S D=$ 26.66) than participants in upper-level courses $(M=58.10$, $S D=28.76 ; t(88)=0.51, p=.61)$.

\section{Day-Level Analyses_-Predicting Emotion Immediately After Class}

As shown in Table 3, experiences of flow during class significantly predicted increased positive emotion immediately after class. Flow also significantly predicted increased nondual experiences during class. Nondual experience during class also significantly predicted increased positive emotion after class. When entered together as predictors, both flow and nondual experience during class still predicted positive emotion immediately following class (see Table 3). Because the coefficient for the relationship between flow and positive emotion decreased when accounting for nondual experience, we ran a Sobel test for mediation to investigate whether this decrease was statistically significant - in other words, a Sobel test of mediation provides a formal test of whether or not the formal criteria for statistical mediation are satisfied. Nondual experience significantly mediated the relationship between flow and positive emotion (Sobel $t=4.30, \mathrm{SE}=0.45, p<.001$ ).

Flow experienced during class significantly predicted less negative emotion after class. Nondual experience during class also significantly predicted less negative emotion after class. When entered together as predictors, flow predicted less negative emotion after class, but nondual experience did not predict negative emotion (see Table 4). A Sobel test of mediation showed that nondual experience did not mediate the relationship between flow and negative emotion (Sobel $t=0.06, \mathrm{SE}=$ $0.32, p=.95)$.

\section{Longitudinal Analyses-Predicting Psychological and Subjective Well-Being}

As shown in Table 5, grand flow significantly predicted wellbeing scores on Week 4, such that higher flow scores predicted higher psychological well-being at the end of the four weeks. Grand flow also predicted well-being on Week 4 when

Table 4 Results of mixed linear models examining the day-level relationships between flow, nondual experience, and negative emotion

\begin{tabular}{|c|c|c|c|c|c|c|c|}
\hline & \multirow[t]{2}{*}{$\mathrm{b}$} & \multirow[t]{2}{*}{ SE } & \multirow[t]{2}{*}{$N$} & \multicolumn{2}{|l|}{$95 \% \mathrm{CI}$} & \multirow[t]{2}{*}{$t$} & \multirow[t]{2}{*}{$p$} \\
\hline & & & & Lower & Upper & & \\
\hline Flow predicting Neg. Emotion & -3.88 & 0.69 & 329 & -5.19 & 2.34 & -5.62 & $<.001$ \\
\hline Flow predicting Nondual Experience & 16.26 & 2.28 & 329 & 12.08 & 20.86 & 7.13 & $<.001$ \\
\hline Nondual Experience predicting Neg. Emotion & -0.04 & 0.02 & 328 & -0.07 & -0.002 & -2.18 & .03 \\
\hline Flow predicting Neg. Emotion controlling for Nondual Experience & -3.90 & 0.76 & 328 & -5.31 & -2.30 & -5.10 & $<.001$ \\
\hline Nondual Experience Predicting Neg. Emotion controlling for Flow & 0.001 & 0.02 & 328 & -0.04 & 0.04 & 0.06 & .95 \\
\hline
\end{tabular}

b indicates unstandardized coefficients. Flow = the mean of the participants' scores on the Flow State Scale (Jackson \& Marsh, 1996) measured immediately after class each week; Nondual Experience = the mean of the participants' scores on the Nondual Awareness Dimensional Assessment measured immediately after class each week, questions adapted from the NADA-Trait scale (Hanley et al., 2018) to reflect a state measure; Neg. Emotion $=$ the mean of the participants' scores on the negative emotion items of the Positive and Negative Affect Scales (Watson et al., 1988) measured immediately after class each week. Results of the Sobel test for mediation are reported in text 
Table 5 Results of multiple regressions predicting psychological well-being at Week 4

Psychological Well-Being Week 4

\begin{tabular}{|c|c|c|c|c|c|c|}
\hline \multirow[t]{2}{*}{ Predictor } & \multirow[t]{2}{*}{$\mathrm{b}$} & \multirow[t]{2}{*}{ SE } & \multicolumn{2}{|l|}{$95 \% \mathrm{CI}$} & \multirow[t]{2}{*}{$t$} & \multirow[t]{2}{*}{$p$} \\
\hline & & & Lower & Upper & & \\
\hline Grand Flow & 0.49 & 0.13 & 0.23 & 0.74 & 3.77 & $<.001$ \\
\hline Grand Nondual Experience & 0.003 & 0.002 & -0.002 & 0.007 & 1.20 & .24 \\
\hline Grand Flow & 0.63 & 0.17 & 0.30 & 0.96 & 3.81 & $<.001$ \\
\hline Grand Nondual Experience & -0.003 & 0.003 & -0.01 & 0.002 & -1.38 & .173 \\
\hline Grand Flow & 0.32 & 0.14 & 0.05 & 0.60 & 2.34 & .02 \\
\hline Grand Nondual Experience & -0.003 & 0.002 & -0.01 & 0.001 & -1.54 & .13 \\
\hline Psych. Well-Being Week 1 & 0.56 & 0.09 & 0.40 & 0.73 & 6.67 & $<.001$ \\
\hline
\end{tabular}

Grand Flow = the mean of the participants' scores on the Flow State Scale (Jackson \& Marsh, 1996) averaged across all four weeks; Grand Nondual Experience $=$ the mean of the participants' scores on the Nondual Awareness Dimensional Assessment averaged across all four weeks, questions adapted from the NADA-Trait scale (Hanley et al., 2018) to reflect a state measure; Psych. Well-Being = the participants' mean scores on the Psychological WellBeing Scale (Ryff \& Keyes, 1995). Regression table of unstandardized coefficients of the relationship between the predictor variable(s) and psychological well-being at Week 4 as the outcome variable for all four models: (1) grand flow as predictor, (2) grand nondual experience as predictor, (3) grand flow and grand nondual experience as predictors, and (4) grand flow, grand nondual experience, and psychological well-being at Week 1 as predictors $(N=76)$

controlling for well-being on Week 1, suggesting that flow experience also predicted a positive change in psychological well-being over the four-week time period. As shown in Table 5, the grand mean of nondual experience did not significantly predict Week 4 well-being in any of the regression models examined.

In addition to examining psychological well-being, we also examined satisfaction with life as a dependent variable. As shown in Table 6, the grand means of both nondual experience and flow were positively associated with Week 4 satisfaction with life when entered as individual predictors.
However, when the grand means of flow and nondual experience were both included simultaneously as predictors of Week 4 satisfaction with life, only nondual experience remained a significant predictor-flow was no longer significantly associated with satisfaction with life. We then ran the Sobel test for mediation to investigate whether nondual experience mediated the relationship between flow experience and reported satisfaction with life at Week 4. We found that nondual experience mediated the relationship between flow and satisfaction with life (Sobel $t=1.94, \mathrm{SE}=1.06, p=.05$ ).

Table 6 Results of multiple regressions predicting satisfaction with life at Week 4

\begin{tabular}{|c|c|c|c|c|c|c|}
\hline \multirow{3}{*}{ Predictor } & \multicolumn{6}{|c|}{ Satisfaction with Life Week 4} \\
\hline & $\mathrm{b}$ & SE & $95 \% \mathrm{CI}$ & & $t$ & $p$ \\
\hline & & & Lower & Upper & & \\
\hline Grand Flow & 4.37 & 1.54 & 1.31 & 7.44 & 2.85 & .01 \\
\hline Grand Nondual Experience & 0.08 & 0.02 & 0.03 & 0.13 & 3.43 & .001 \\
\hline Grand Flow & 1.88 & 1.93 & -1.97 & 5.73 & 0.97 & .34 \\
\hline Grand Nondual Experience & 0.06 & 0.03 & 0.002 & 0.12 & 2.06 & .04 \\
\hline Grand Flow & 0.34 & 1.58 & -2.80 & 3.47 & 0.21 & .83 \\
\hline Grand Nondual Experience & 0.05 & 0.02 & -.003 & 0.09 & 1.87 & .07 \\
\hline Satisfaction with Life Week 1 & 0.66 & 0.10 & 0.45 & 0.87 & 6.39 & $<.001$ \\
\hline
\end{tabular}

Grand Flow = the mean of the participants' scores on the Flow State Scale (Jackson \& Marsh, 1996) averaged across all four weeks; Grand Nondual Experience $=$ the mean of the participants' scores on the Nondual Awareness Dimensional Assessment averaged across all four weeks, questions adapted from the NADA-Trait scale (Hanley et al., 2018) to reflect a state measure; Satisfaction with Life = Participants' scores on the Satisfaction with Life Scale (Diener et al., 1985). Regression table of standardized coefficients of the relationship between the predictor variable(s) and satisfaction with life at Week 4 as the outcome variable for all four models: (1) grand flow as predictor, (2) grand nondual experience as predictor, (3) grand flow and grand nondual experience as predictors, and (4) grand flow, grand nondual experience, and satisfaction with life at Week 1 as predictors

$(N=76)$ 
As shown in Table 6, when controlling for Week 1 satisfaction with life, neither flow nor nondual experience were significantly associated with Week 4 satisfaction with life, indicating that neither variable was associated with change in life satisfaction over time.

\section{Exploratory Analyses}

All nine dimensions of the flow state significantly correlated with the two dimensions of nondual experience except for loss of self-consciousness and self-transcendence (see Table 7).

\section{Discussion}

The purpose of the present investigation was to understand the potential relationships between the flow state, nondual experiences, and well-being. We found that experiences of flow and nonduality are highly positively correlated with one another, suggesting that flow demonstrates similarities to certain forms of meditation, in particular, kinds that focus on cultivating a nondual, or unitary experience between subject and object. The relationship between flow and nonduality suggests that nondual experiences may be accessed through avenues beyond the context of meditation, as suggested by Hanley et al. (2018) and tested here. Furthermore, the finding that participants in introductory courses did not differ substantially from those in upper-level courses regarding scores on the flow or nonduality assessments suggests that at least some aspects of flow states and nondual experiences are accessible to non-experts. This finding is in line with the evidence found by Berman and Stevens (2015) that suggests individuals with low expertise still had nondual experiences during meditation, although these experiences were probably not sustained for as long as those with greater expertise.

Overall, we found that both flow and nondual experiences significantly predicted increased positive emotion immediately following the various arts classes across all four weeks (one day per week, for four weeks). Flow also predicted a decrease in negative emotion across all four weeks, while nondual experience did not. The finding that flow predicted increased positive emotion and decreased negative emotion supports previous work suggesting that a flow-inducing game of Tetris can serve as a way to regulate emotions during a stressful waiting period (Rankin et al., 2018). Surveying participants immediately after their classes allowed us to assess flow experience in a more immediate sense compared to retrospective accounts or measures of dispositional traits. The current study also extends previous work on experiences of flow in sports by demonstrating that playing music, acting, dancing, and many other creative activities do indeed produce a state of flow, which also have important benefits for emotion regulation and well-being (Adey, 2018; Wrigley \& Emmerson, 2011).

We found that while flow experience was associated with decreased negative emotions, nondual experience was not. Given that nondual awareness dissolves subject-object boundaries, it could be that this alteration in self-concept encourages a more acceptance-based approach to negative emotions while cultivating positive ones, rather than specifically trying to get rid of negative emotions. The lack of influence on negative emotions also suggests that experiences of nonduality contain distinct features from mere distraction or self-distancing given that these other techniques of emotion regulation have been found to decrease negative emotions specifically (Joormann et al., 2007; Sheppes \& Meiran, 2007, 2008). Additionally, mere distraction may be harmful in the long-term by promoting emotional avoidance (Roth \& Cohen, 1986; Sheppes \&
Table 7 Correlations between the nine dimensions of the Flow State Scale and the two dimensions of the Nondual Awareness Dimensional Assessment

\begin{tabular}{|c|c|c|c|c|}
\hline \multirow[b]{3}{*}{ Flow State Scale } & \multicolumn{4}{|c|}{ Nondual Awareness Dimensional Assessment } \\
\hline & \multicolumn{2}{|c|}{ Self-transcendence } & \multicolumn{2}{|c|}{ Bliss } \\
\hline & $\mathrm{r}$ & $p$ & $\mathrm{r}$ & $p$ \\
\hline Challenge-skill balance & .26 & .011 & .32 & .002 \\
\hline Action-awareness merging & .33 & .001 & .32 & .002 \\
\hline Clear goals & .39 & $<.001$ & .40 & $<.001$ \\
\hline Unambiguous feedback & .40 & $<.001$ & .36 & $<.001$ \\
\hline Concentration & .35 & .001 & .46 & $<.001$ \\
\hline Transformation of time & .54 & $<.001$ & .47 & $<.001$ \\
\hline Autotelic experience & .46 & $<.001$ & .63 & $<.001$ \\
\hline Paradox of control & .29 & .004 & .38 & $<.001$ \\
\hline Loss of self-consciousness & .15 & .144 & .20 & .05 \\
\hline
\end{tabular}

Correlations are (2-tailed)

$N=94$ 
Meiran, 2007, 2008). On the other hand, leaving negative emotions alone, as in acceptance-based strategies, can also be a beneficial practice because it requires less cognitive burden, encourages a deeper understanding of the negative experience, and still leads to increased psychological well-being in the long-run (Ford et al., 2018).

Furthermore, we found support for the hypothesis that nondual experience serves as a mediator of the relationship between flow experience and positive emotion. The term nonduality encompasses a unified experience in which the boundaries between self and environment dissolve. This experience of nonduality seems to underlie the experience of flow. Certain aspects of flow allude to features of nonduality, such as a merging of a person's awareness with the action being performed, alteration of time, deep concentration, and intrinsic motivation to perform the activity for the sake of itself. Indeed, flow and nondual experience correlate with one another. Yet, nonduality captures a great distinction in how a person perceives themselves and their relations to the world. Rather than merely a loss of self-conscious worry or concern, our findings here suggest that a person's self becomes integrated with the activity during a state of flow. The integration of subject and object may allow a person's emotions to be acknowledged, expressed, and processed through the activity. As a perspective of nonduality emerges, an understanding of unity between self and other is encouraged which may aid in the therapeutic process (Blackstone, 2015). The "loss of self-consciousness" dimension of flow was not significantly correlated with the "self-transcendence" dimension of nondual experience, suggesting that experiencing nonduality captures a specific alteration in the self-concept that flow experience alone does not seem to account for.

We also found that mean flow experience over the course of the four weeks predicted a significant positive change in psychological well-being at the end of the four weeks. This finding that flow predicted change in well-being is rather robust, given the stability typically observed in measures of global well-being (Ryff \& Keyes, 1995). However, nondual experience did not predict psychological well-being. Instead, nondual experience significantly predicted satisfaction with life. While flow also predicted satisfaction with life on its own, the relationship lost significance when accounting for nondual experience. Thus, nondual experience mediated the relationship between flow and satisfaction with life. This suggests that flow and nondual experience relate to different aspects of global well-being, despite their similarity in predicting positive emotion in the short-term.

However, past work has suggested that flow experience (Fritz \& Avsec, 2007; Wrigley \& Emmerson, 2011), and mindfulness (Hanley et al., 2015) influence both subjective and psychological well-being. It could be that although participants reported the presence of nondual experiences, they did not necessarily engage in overt mindfulness or contemplative practices. Exploratory work by Hanley et al. (2015) found that non-practitioners may conceptualize subjective and psychological well-being as more distinct forms of well-being than practitioners. It could be that the sample in the current study primarily consisted of non-practitioners, which may explain why flow and nondual experience predicted different aspects of well-being. However, because we did not ask participants about their engagement in mindfulness practices, it is difficult to say what influenced the differences in subjective and psychological well-being. More research is needed to understand how and why flow and nondual experience seem to predict different aspects of well-being, and if this difference is driven by other factors, such as having a well-established mindfulness practice.

The current study expands the literature on flow, well-being, and contemplative science in important ways. We aimed to facilitate dialogue and translation between the literature on flow states and that of nonduality and nondual experiences. Additionally, our finding that states of flow and nondual experiences are associated with increased positive emotion in the short-term (and flow is associated with decreased negative emotion in the short-term) suggests that creative and expressive activities are particularly powerful at regulating and processing emotions. Additionally, we found that flow and nondual experiences are associated with greater well-being, and that flow may share important similarities with meditation and the concept of nonduality referenced in many philosophical and religious traditions.

\section{Limitations and Future Directions}

The concept of nondual awareness appears in schools of Hindu thought, such as Advaita Vedānta and Kashmiri Shaivism, as well as, Tibetan Bon Dzogchen and Mahāyāna Buddhism, all of which contain a philosophy of nonduality between subject and object (Blackstone, 2015; Krägeloh, 2018). As concepts of nondual awareness enter the realm of scientific research, uncertainty arises regarding how a "pure" nondual awareness that is free from mental concepts and phenomenology might be reported or studied. Currently, nondual awareness - when fully realized - seems to have different neural markers and contents of experience than simply having an experience with nondual content, for the exact reason that fully realized nondual awareness is free of content and realizes itself spontaneously (Josipovic, 2014, 2019). The very use of the Nondual Awareness Dimensional Assessment (Hanley et al., 2018) in capturing experiences with a nondual nature means that the participants in our study were reporting on their felt effects of experiencing nonduality, while most likely not having fully realized nondual awareness in its purest sense. Nevertheless, ours and similar endeavors help the contemplative sciences gain a better understanding of individuals' experiences with these features of consciousness (Josipovic, 2010, 2014, 2019; Krägeloh, 2018). Although the true nature of nondual awareness may be 
impossible to completely capture linguistically (and is better understood through direct experience), these methods still serve as a useful window into what these experiences may be like and what potential benefits they have. Additionally, it is likely that many participants might have been unfamiliar with the terminology used in the scale items to describe nonduality. Despite possible unfamiliarity, participants seemed to respond in a meaningful way to the scale items, suggesting that exposure did not drive the nature of their responses.

It is important to note that the correlational design of the current study limits its scope in making causal claims about how flow and nondual experience might contribute to wellbeing, both at the day-level and longitudinally. Further research is needed to investigate the specific avenues through which flow activities might facilitate cognitive shifts and lead to the regulation of emotions. Nondual experiences seemed to capture one type of cognitive shift taking place during the flow state, but an experimental design could more directly test the cognitive changes taking place, such as the study by Rankin et al. (2018) which used a Tetris manipulation. For example, future work could investigate how flow-activities might regulate emotions in similar ways to meditation, acceptance-based strategies, or distraction. Flow seems related to these other strategies, yet encompasses creative and behavioral aspects that meditation, acceptance, and distraction may not completely explain. By using experimental designs, future studies could more clearly examine how engaging in flow activities and nondual experiences may immediately affect emotions before and after a flow-activity manipulation.

Although meditation encompasses many different techniques, flow at least seems to share the aspect of nondual experience. In flow states, people may also experience selftranscendence and an integration of self and environment despite the differences in where and how these activities are performed. Contemplative science should continue investigating the flow state and how it compares to other forms of contemplative practice. Aside from the dance practices and classes, the current study did not survey individuals during sports or exercise in order to keep the focus primarily centered on the arts. However, conducting a similar study in a sample of athletes could demonstrate the validity and generalizability of our results to other contexts. In addition, the physiological and neurological aspects of flow and nondual experiences could be compared to further understand their nature across various contexts and disciplines.

Overall, the robust relationships found here suggest that engaging in activities which cultivate flow states and nondual experiences may have important implications for psychological health that need to be further explored. While flow activities are often underestimated and regarded as simple hobbies, the mental states and outcomes they produce are quite profound (Blackstone,
2015; Csikszentmihalyi, 2014). Further research is needed to fully understand the therapeutic benefits of flow activities and nondual experiences. Beyond the contexts of yoga and meditation, future scientific endeavors could examine how flow and nonduality intersect with other mindfulness-based practices which promote psychological, biological, and spiritual benefits (Greeson, 2009). Additionally, flow and nonduality may be especially prominent within the domains of recreation and art therapies, as these areas also adopt a holistic approach to healing the body, mind, and spirit (Bien, 2005; Hughes \& da Silva, 2011; Svensk et al., 2009). Understanding how these relationships translate to daily life and coping is an extensive and worthwhile avenue for future studies.

Acknowledgements The authors would like to thank all of the participants for their openness and willingness to enroll in this study and answer questions about their creative processes. The authors would also like to thank Josh Rottman, David McMahan, and Michael Penn for providing feedback on a previous version of this manuscript.

Author Contribution JML: acquired funding, designed, and conducted the study, performed data analysis, and drafted the manuscript. AST: supervised the study, assisted data analysis, and collaborated in the writing and editing of the final manuscript.

Funding This work was supported by a Brookshire Fellowship from the Franklin \& Marshall College Department of Psychology awarded to JML. Funding for open access provided by the Franklin \& Marshall College Open Access Publishing Fund.

Data Availability All data are available on the Open Science Framework website. (https://osf.io/hf7z5/).

\section{Declarations}

Ethics Approval The current study was approved by the Franklin \& Marshall College IRB and the authors certify that the study was performed in accordance with the ethical standards.

Consent to Participate Informed consent was obtained from all individual participants included in the study.

Conflict of Interest The authors declare no competing interests.

Open Access This article is licensed under a Creative Commons Attribution 4.0 International License, which permits use, sharing, adaptation, distribution and reproduction in any medium or format, as long as you give appropriate credit to the original author(s) and the source, provide a link to the Creative Commons licence, and indicate if changes were made. The images or other third party material in this article are included in the article's Creative Commons licence, unless indicated otherwise in a credit line to the material. If material is not included in the article's Creative Commons licence and your intended use is not permitted by statutory regulation or exceeds the permitted use, you will need to obtain permission directly from the copyright holder. To view a copy of this licence, visit http://creativecommons.org/licenses/by/4.0/. 


\section{References}

Adey, K. L. (2018). Understanding why women knit: finding creativity and "flow". Textile: The Journal of Cloth and Culture, 16(1), 84-97. https://doi.org/10.1080/14759756.2017.1362748.

de Bary, W. T., \& Bloom, I. (1968). Sources of Chinese tradition (Vol. 1, 2nd ed.pp. 95-111). New York, NY: Columbia University Press.

Bates, D., Mächler, M., Bolker, B., \& Walker, S. (2015). Fitting linear mixed-effects models using lme4. Journal of Statistical Software, 67(1), 1-48. doi: 10.18637/jss.v067.i01.

Berman, A. E., \& Stevens, L. (2015). EEG manifestations of nondual experiences in meditators. Consciousness and Cognition, 31, 1-11.

Bien, M. B. (2005). Art therapy as emotional and spiritual medicine for Native Americans living with HIV/AIDS. Journal of Psychoactive Drugs, 37(3), 281-292.

Blackstone, J. (2015). Intersubjectivity and nonduality in the psychotherapeutic relationship. The Journal of Transpersonal Psychology, 38(1), 25-40.

Bulmer, M. G. (1979). Principles of Statistics. (Rev. ed.). New York: Dover Publications.

Collins, A. L., Sarkisian, N., \& Winner, E. (2009). Flow and happiness in later life: an investigation into the role of daily and weekly flow experiences. Journal of Happiness Studies: An Interdisciplinary Forum on Subjective Well-Being, 10(6), 703-719. https://doi.org/ 10.1007/s10902-008-9116-3.

Connolly, C. T., \& Tenenbaum, G. (2010). Exertion-attention-flow linkage under different work loads. Journal of Applied Social Psychology, 40(5), 1123-1145.

Csikszentmihalyi, M. (2014). Flow and the foundations of positive psychology. New York: Springer.

Diener, E., Emmons, R. A., Larsen, R. J., \& Griffin, S. (1985). The satisfaction with life scale. Journal of Personality Assessment, 49, 71-75.

Dorjee, D. (2016). Defining contemplative science: the metacognitive self-regulatory capacity of the mind, context of meditation practice and modes of existential awareness. Frontiers in Psychology, 7(1788), 1-15. https://doi.org/10.3389/fpsyg.2016.01788.

Dunne, J. D., Thompson, E., \& Schooler, J. (2019). Mindful meta-awareness: sustained and nonpropositional. Current Opinion in Psychology, 28, 307-311.

Enders, C. K., \& Tofighi, D. (2007). Centering predictor variables in cross-sectional multilevel models: a new look at an old issue. Psychological Methods, 12(2), 121-138.

Ford, B. Q., Lam, P., John, O. P., \& Mauss, I. B. (2018). The psychological health benefits of accepting negative emotions and thoughts: laboratory, diary, and longitudinal evidence. Journal of Personality and Social Psychology, 115(6), 1075-1092.

Fritz, B. S., \& Avsec, A. (2007). The experience of flow and subjective well-being of music students. Horizons of Psychology, 16(2), 5-17.

George, D., \& Mallery, M. (2010). SPSS for Windows step by step: a simple guide and reference, 17.0 update (10a ed.). Boston: Pearson.

Greeson, J. M. (2009). Mindfulness research update: 2008. Complementary Health Research Practice Review, 14, 10-18.

Gross, J. J. (1998). The emerging field of emotion regulation: an integrative review. Review of General Psychology, 2(5), 271-299. https:// doi.org/10.1037/1089-2680.2.3.271.

Hanley, A., Warner, A., \& Garland, E. L. (2015). Associations between mindfulness, psychological well-being, and subjective well-being with respect to contemplative practice. Journal of Happiness Studies, 16, 1423-1436. https://doi.org/10.1007/s10902-014-9569-5.

Hanley, A. W., Nakamura, Y., \& Garland, E. L. (2018). The nondual awareness dimensional assessment (NADA): new tools to assess nondual traits and states of consciousness occuring within and beyond the context of meditation. Psychological Assessment, 30(12), 1625-1639.
Hughes, E. G., \& da Silva, A. M. (2011). A pilot study assessing art therapy as a mental health intervention for subfertile women. Human Reproduction, 26(3), 611-615.

Jackson, S. A., \& Marsh, H. W. (1996). Development and validation of a scale to measure optimal experience: the flow state scale. Journal of Sport \& Exercise Psychology, 18, 17-35.

Jackson, S. A., Thomas, P. R., Marsh, H. W., \& Smethurst, C. J. (2001). Relationships between flow, self-concept, psychological skills, and performance. Journal of Applied Sport Psychology, 13, 129-153.

Joormann, J., Siemer, M., \& Gotlib, I. H. (2007). Mood regulation in depression: differential effects of distraction and recall of happy memories on sad mood. Journal of Abnormal Psychology, 116(3), 484-490. https://doi.org/10.1037/0021-843X.116.3.484.

Josipovic, Z. (2010). Duality and nonduality in meditation research. Consciousness and Cognition, 19(4), 1119-1121.

Josipovic, Z. (2014). Neural correlates of nondual awareness in meditation. Annals of the New York Academy of Sciences, 1307(1), 9-18.

Josipovic, Z. (2019). Nondual awareness: consciousness-as-such as nonrepresentational reflexivity. In N. Srinivasan (Ed.), Progress in brain research: Meditation, Vol. 244. (p. 273-298). Elsevier Academic Press. https://doi.org/10.1016/bs.pbr.2018.10.021

Krägeloh, C. (2018). Phenomenological research fails to capture the experience of nondual awareness. Mindfulness. https://doi.org/10. 1007/s12671-018-0995-z.

Lao Tzu. (1991). Dao de jing. (A. C. Muller Trans.) [Online publication]. Retrieved November 18, 2018, from http://www.acmuller.net/condao/daodejing.html. (Original work published in 4th century BC).

Leary, M. R., \& Gohar, D. (2014). Self-awareness and self-relevant thought in the experience and regulation of emotion. In J. J. Gross (Ed.), Handbook of emotion regulation (2nd ed., pp. 376-389). New York: The Guilford Press.

McGonigal, K. M. (2015). The upside of stressk. New Yor. NY: Avery.

Mills, P. J., Peterson, C. T., Pung, M. A., Patel, S., Weiss, L., Wilson, K. L., Doraiswamy, P. M., Martin, J. A., Tanzi, R. E., \& Chopra, D. (2018). Change in sense of nondual awareness and spiritual awakening in response to a multidimensional well-being program. Journal of Alternative and Complementary Medicine, 24(4), 343351. https://doi.org/10.1089/acm.2017.0160.

R Core Team (2015). R: A language and environment for statistical computing. R Foundation for Statistical Computing, Vienna. https://www.r-project.org/

Rankin, K., Walsh, L. C., \& Sweeny, K. (2019). A better distraction: exploring the benefits of flow during uncertain waiting periods. Emotion, 19(5), 818-828. https://doi.org/10.1037/emo0000479.

Roth, S., \& Cohen, L. J. (1986). Approach, avoidance, and coping with stress. The American Psychologist, 41(7), 813-819. https://doi.org/ 10.1037/0003-066X.41.7.813.

Ryan, R. M., \& Deci, E. L. (2001). On happiness and human potentials: a review of research on hedonic and eudaimonic well-being. Annual Review of Psychology, 52(1), 141-166. https://doi.org/10.1146/ annurev.psych.52.1.141.

Ryff, C. D. (1989). Happiness is everything, or is it? Explorations on the meaning of psychological well-being. Journal of Personality and Psychology, 57(6), 1069-1081. https://doi.org/10.1016/j.rgmx. 2013.06.038.

Ryff, C. D., \& Keyes, C. L. M. (1995). The structure of psychological well-being revisited. Journal of Personality and Social Psychology, 69(4), 719-727.

Sheppes, G., \& Meiran, N. (2007). Better late than never? On the dynamics of online regulation of sadness using distraction and cognitive reappraisal. Personality and Social Psychology Bulletin, 33(11), 1518-1532.

Sheppes, G., \& Meiran, N. (2008). Divergent cognitive costs for online forms of reappraisal and distraction. Emotion, 8(6), 870-874.

Svensk, A. C., Öster, I., Thyme, K. E., Magnusson, E., Sjödin, M., Eisemann, M., Åström, S., \& Lindh, J. (2009). Art therapy improves experienced quality of life among women undergoing treatment for 
breast cancer: a randomized controlled study. European Journal of Cancer Care, 18, 69-77.

Watson, D., Clark, L. A., \& Tellegen, A. (1988). Development and validation of brief measures of positive and negative affect: the PANAS scales. Journal of Personality and Social Psychology, 54(6), 1063-1070.

Wright, R. (2017). Why Buddhism is true: the science and philosophy of meditation and enlightenment. Simon \& Schuster.
Wrigley, W. J., \& Emmerson, S. B. (2011). The experience of the flow state in live music performance. Psychology of Music, 41(3), 292305. https://doi.org/10.1177/0305735611425903.

Publisher's Note Springer Nature remains neutral with regard to jurisdictional claims in published maps and institutional affiliations. 